\title{
Nucleophilic Attack at the Pyridine Nitrogen Atom in a Bis(imino)pyridine System: The Local Hard and Soft Acids and Bases Principle Perspective
}

\author{
Arlette Richaud and Francisco Méndez* \\ Departamento de Química, División de Ciencias Básicas e Ingeniería, Universidad Autónoma Metropolitana-Iztapalapa, A.P. \\ 55-534, México, D.F., 09340 México.
}

Dedicated to José Luis Gázquez

Received January 06, 2012; accepted June 04, 2012

\begin{abstract}
Motivated by the unprecedented nucleophilic attack at the pyridine nitrogen atom in bis(imino)pyridines, observed by Gambarotta et al. and Gibson et al., and the fact that normally pyridine undergoes reactions with electrophiles at its nitrogen atom, we applied the local hard and soft acids and bases principle to assert that nucleophilic attack at pyridine nitrogen atom depends fundamentally on stereoelectronic factors.
\end{abstract}

Key words: Nucleophilic reactivity, bis(imino)Pyridines, Stereoelectronic Factors.

\section{Introduction}

The diimine/pyridine ligand system enhances the reactivity of early and late transition metals toward olefin polymerization [1-3]. The six electron donor 2,6-bis(imino)pyridines $\mathbf{1}$ are tridentate ligands with potentially reactive nitrogen and carbon atoms (Figure 1) [4, 5].

In order to afford novel $[N, N, N]$ ligands, Gibson et al. described the reaction of $d_{6}$-bis(imino)pyridines 2 with $\mathrm{MeLi}$ which provides the new ligand $\mathbf{3}$ arising from nucleophilic attack at the pyridine atom (Scheme 1). The $N$-methylation was unequivocally confirmed by a single-crystal X-ray diffraction experiment [6]. In a parallel study, Gambarotta et al. found that reaction of bis(imino)pyridine with MeLi leads to the surprising alkylation at the pyridine nitrogen atom [7]. These reactions were unprecedented because pyridine derivatives in general undergo reactions with nucleophiles at the $\alpha$ and $\gamma$ positions or, under special circumstances at the $\beta$ positions of the pyridine ring.

Gibson et al. surmised that "This highly selective nucleophilic attack at pyridine nitrogen is believed to arise from a

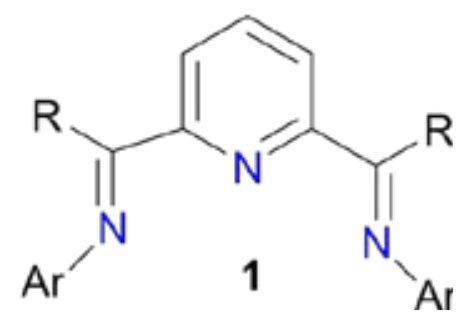

Fig. 1. Schematic representation of the electron donor 2,6bis(imino)pyridine ligand.
Resumen. Motivados por el ataque nucleofílico sin precedentes sobre el átomo de nitrógeno de la piridina en bis(imino)piridinas observado por Gambarotta et al. y Gibson et al. y por el hecho de que normalmente la piridina reacciona con electrófilos en el átomo de nitrógeno, aplicamos el principio de ácidos y bases duros y blandos para confirmar que el ataque nucleofílico al átomo de nitrógeno de la piridina depende fundamentalmente de factores estereoelectrónicos.

Palabras clave: Reactividad nucleofílica, bis(imino)piridinas, factores estereoelectrónicos.

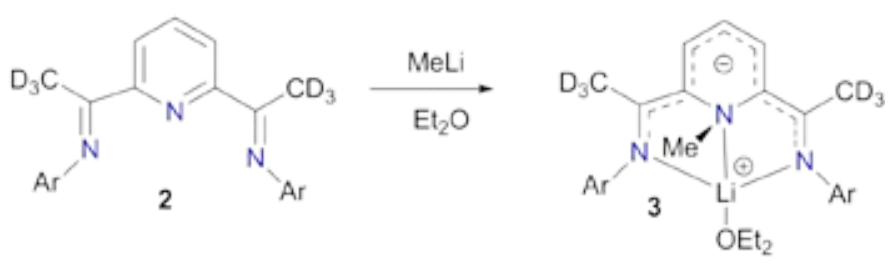

Scheme 1. $[N, N, N]$ ligands obtained by nucleophilic attack at the pyridine atom of $d_{6}$-bis(imino)pyridines.

combination of favourable circumstances: (i) di-ortho substitution of the aryl ring Ar that effectively shields the imino-carbon from nucleophilic attack, (ii) deuterium substitution at the ketimine position disfavouring proton (deuteron) abstraction and (iii) chelation of MeLi by the pyridine and imino nitrogen donors places the MeLi in a favorable position for methyl migration to the pyridine nitrogen".

The local HSAB principle, proposed and proved by minimization of the grand canonical potential by Gázquez and Méndez $[8,9]$, is a successful principle of reactivity based on density functional theory (DFT) local descriptors (Fukui function $f(\mathbf{r})$ and local softness $s(\mathbf{r}))$ [10-12]. It establishes that although the softest atom in molecule $A$ is in general the most reactive site, there may be other less soft sites, which may become the most reactive sites, regulated by the softness of the reacting molecule $B[8,9]$. The local HSAB principle has been widely used in studies on multiple reaction sites and in strong and weak chemical interactions [13-19].

In this study we reveal, using the local HSAB principle and DFT local descriptors, that nucleophilic attack at the pyridine nitrogen atom of $\mathbf{1}$ depends fundamentally on stereoelectronic factors (for a description of stereolectronic effects see Juaristi and Cuevas [20]. 


\section{Computational Details}

The geometries of the minima of the potential energy surface for the reference molecules $\mathbf{4}, \mathbf{5 a}$, and $\mathbf{6}$ were calculated at the B3LYP/6-311+G(2d,2p) level of theory using GAUSSIAN03 [21]. For $\mathbf{5 b}$ and $\mathbf{7}$, the experimental geometry obtained by Xray diffraction [6] was used. The nucleophilic Fukui function $f^{+}(\mathbf{r})$ and local softness $\mathrm{s}^{+}(\mathbf{r})$ for 4-7 were calculated using $f^{+}(\mathbf{r})=\rho_{\mathrm{N}+1}(\mathrm{r})-\rho_{\mathrm{N}}(\mathrm{r})$ and $\mathrm{s}^{+}(\mathbf{r})=\mathrm{S} f^{+}(\mathbf{r})$, where $\mathrm{S}$ is the global softness (inverse of the chemical hardness $\eta$ ) and $\rho_{N}(\mathbf{r})$ and $\rho_{\mathrm{N}+1}(\mathbf{r})$ are the electronic density of the reference molecule and its corresponding anion respectively. The $\eta$ value was obtained from the ionization potential $(I)$ and the electron affinity $(A)$, $\eta=(I-A) / 2$. The $f^{+}(\mathbf{r})$ isosurface diagrams were plotted with GaussView [22].

\section{Results and Discussion}

In order to observe systematically how the pyridine nitrogen atom acquires electrophilic character and analyze the proposals made by Gibson et al. (i.e. i-iii), we studied the precursor 2,6-diacetylpyridine $4\left(\mathrm{R}=\mathrm{CH}_{3}\right)$, the $[N, N, N]$ ligand bis(imino)-pyridine 5 $\left\{\left[2,6-(\mathrm{ArNCR}){ }_{2} \mathrm{C}_{5} \mathrm{H}_{3} \mathrm{~N}\right]\right\} \quad\left[\mathrm{R}=\mathrm{CH}_{3}, \mathrm{Ar}=\mathrm{Ph}, 2,6-i-\mathrm{Pr}_{2} \mathrm{C}_{6} \mathrm{H}_{3}\right]$, the complex with $\mathrm{MeLi}\left\{\left[2,6-(\mathrm{ArNCCH})_{2} \mathrm{C}_{5} \mathrm{H}_{3} \mathrm{~N}\right]\right\} \mathrm{LiMe}[\mathrm{Ar}=2,6-$ $\left.i-\mathrm{Pr}_{2} \mathrm{C}_{6} \mathrm{H}_{3}\right]$ 6, and the complex with $\mathrm{MeLi}$ and $\mathrm{Et}_{2} \mathrm{O}\{[2,6-$ $\left.\left.(\mathrm{ArNCCH})_{2} \mathrm{C}_{5} \mathrm{H}_{3} \mathrm{~N}\right]\right\} \mathrm{Li}(\mathrm{Me})\left(\mathrm{Et}_{2} \mathrm{O}\right) \quad\left[\mathrm{Ar}=2,6-i-\mathrm{Pr}_{2} \mathrm{C}_{6} \mathrm{H}_{3}\right] 7$ (Figure 2).

The analysis of Figure 3 shows the nucleophilic Fukui function $f^{+}(\mathbf{r})$ isosurface diagram for $\mathbf{4}$ (magenta colors correspond to positive $f^{+}(\mathbf{r})$ values; cutting value 0.01 a.u.). The diagram shows the reactive sites for $\mathbf{4}$ to a given soft nucleophile. According to the local HSAB principle, the softness of the nucleophile should be within the same range or value as the preferred site in order to react in the studied molecule, i.e. $s^{+}(\mathbf{r})$ $=\mathrm{S} f^{+}(\mathbf{r})$. Higher $f^{+}(\mathbf{r})$ values are located at the $\beta$ positions of the ring followed by the carbonyl group of 4 ; no contribution is observed for the pyridine nitrogen atom. According to the local HSAB principle, the $\beta$-position and the carbonyl carbon atom will react with soft and less soft nucleophiles respectively. In a fashion analogous to the 1,4-Michael addition of nucleophiles to $\alpha, \beta$-unsaturated electrophiles $[13,18,19]$, as observed experimentally [6], the slightly soft nucleophile aniline (hardness $\eta=$ $4.4 \mathrm{eV}$ ) [23] attacks the carbonyl carbon atom to yield $\mathbf{5 a}$.

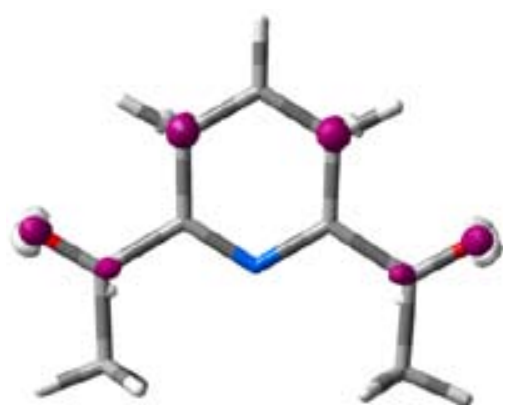

Fig. 3. Isosurface diagram for the nucleophilic Fukui function $f^{+}(\mathbf{r})$ of 4 (magenta colors correspond to positive $f^{+}(\mathbf{r})$ values; cutting value 0.01 a.u.).

The conformational analysis of $\mathbf{5} \mathbf{a}$ shows that the $s$-trans, $s$ trans conformer $\mathbf{5} \mathbf{a}_{\mathbf{t}}$ (Figure 4), is more stable by $12 \mathrm{kcal} \mathrm{mol}^{-1}$ than the $s$-cis,s-cis conformation $\mathbf{5} \mathbf{a}_{\mathbf{c}}$ (Figure 5) However, only in conformer $\mathbf{5} \mathbf{a}_{\mathbf{c}}$, the pyridine nitrogen atom has a contribution to $f^{+}(\mathrm{r})$ (cf. Figures 4 and 5).

From Figure 5 it can be seen that the $s$-cis,s-cis-conformer $\mathbf{5} \mathbf{a}_{\mathbf{c}}$ has the highest $f^{+}(\mathbf{r})$ value at the pyridine nitrogen atom, followed by the imino nitrogen atoms. According to the local HSAB principle, the pyridine nitrogen atom will be attacked by the methyl anion, a soft nucleophile $(\eta=4.0 \mathrm{eV})[6,7,24]$.

Analyzing the calculated values of the $f^{+}(\mathbf{r})$ for $\mathbf{5} \mathbf{b}$ at the experimental geometry of 7 (s-cis,s-cis-conformation; $\mathrm{Ar}=2,6$ $i$ - $\mathrm{Pr}_{2} \mathrm{C}_{6} \mathrm{H}_{3}$ ), we observe in Figure 6 the same behavior of the $f^{+}(\mathbf{r})$ values as in $\mathbf{5} \mathbf{a}_{\mathbf{c}}$; the highest $f^{+}(\mathbf{r})$ values are located at the pyridine nitrogen atom.

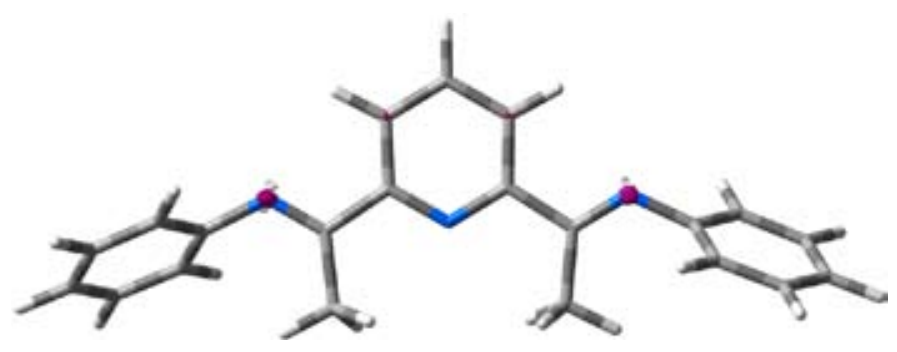

Fig. 4. Isosurface diagrams for the nucleophilic Fukui function $f^{+}(\mathbf{r})$ of the $s$-trans,s-trans-conformer $\mathbf{5 a}_{\mathbf{t}}$; no contribution at the pyridine nitrogen atom is observed (magenta colors correspond to positive $f^{+}(\mathbf{r})$ values; cutting value 0.01 a.u.).

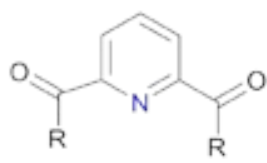

4

$\mathrm{R}=\mathrm{CH}_{3}$

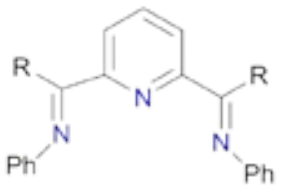

5

5a $\mathrm{R}=\mathrm{CH}_{3} \mathrm{Ar}=\mathrm{Ph}$

$5 b \mathrm{R}=\mathrm{CH}_{3}, \mathrm{Ar}=2,6-i-\mathrm{Pr}_{2} \mathrm{C}_{6} \mathrm{H}_{3}$

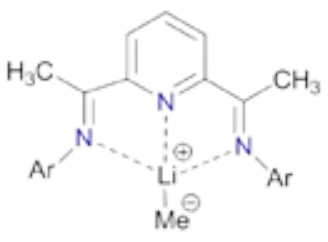

6

$\mathrm{Ar}=2,6-i-\mathrm{Pr}_{2} \mathrm{C}_{6} \mathrm{H}_{3}$

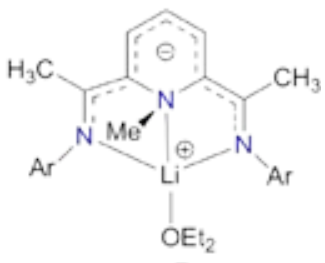

7

$\mathrm{Ar}=2,6-i-\mathrm{Pr}_{2} \mathrm{C}_{6} \mathrm{H}_{3}$

Fig. 2. Structures of the bis(imino)-pyridine compounds studied. 


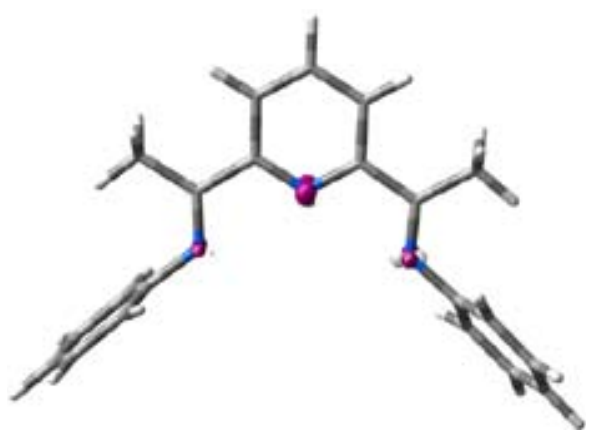

Fig. 5. Isosurface diagrams for the nucleophilic Fukui function $f^{+}(\mathbf{r})$ of the $s$-cis,s-cis-conformer $\mathbf{5} \mathbf{a}_{\mathbf{c}}$; note the contribution at the pyridine nitrogen atom (magenta colors correspond to positive $f^{+}(\mathbf{r})$ values; cutting value 0.01 a.u.).

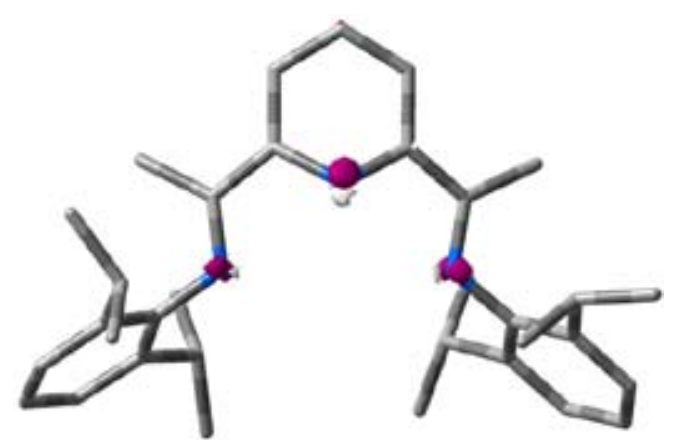

Fig. 6. Isosurface diagrams of the nucleophilic Fukui function $f^{+}(\mathbf{r})$ for $\mathbf{5} \mathbf{b}_{\mathbf{c}}$ with contribution at the pyridine nitrogen atom (magenta colors correspond to positive $f^{+}(\mathbf{r})$ values; cutting value 0.01 a.u. $)$. Hydrogen atoms are omitted for clarity.

Since $\mathbf{5} \mathbf{a}_{\mathbf{c}}$ has no ortho substitution in the $N$-phenyl ring, the nucleophilic attack at the pyridine nitrogen atom does not depend on steric factors. Furthermore, the electrophilic behavior of the pyridine nitrogen atom of $\mathbf{5}$ arises in the s-cis,s-cisconformation and not in the s-trans,s-trans-geometry. Therefore, the nucleophilic attack at the pyridine nitrogen depends fundamentally on stereoelectronic rather than on steric factors (cf. i). The asseveration is corroborated in Figure 7. The $f^{+}(\mathbf{r})$ isosurface diagram for complex $\mathbf{6}$ shows that chelation of $\mathrm{MeLi}$ by the pyridine and imino nitrogen atoms does not modify the $f^{+}(\mathbf{r})$ behavior in the $N, N, N$ ligand; the soft pyridine nitrogen atom continues to be the most reactive site in the molecule for the methyl nucleophilic attack. As a result, the chelation just places the MeLi in a favourable position for methyl migration to the pyridine nitrogen according to the proposal made by Gibson (cf. iii). Calculations at the B3LYP/6-311++G(2df,2pd)// B3LYP/3-21G level of theory showed that transfer of the Libound Me group to the nitrogen atom had low barrier of $5 \mathrm{kcal}$ $\mathrm{mol}^{-1}$ and was exothermic by $26 \mathrm{kcalmol}^{-1}$; the reverse reaction would have a barrier of $31 \mathrm{kcal} \mathrm{mol}^{-1}$ [7]. Gambarotta et al. also reported that pyridine ring becomes slightly more folded and receives more negative charge in the presence of a diethyl ether molecule coordinated to the lithium atom. The reported

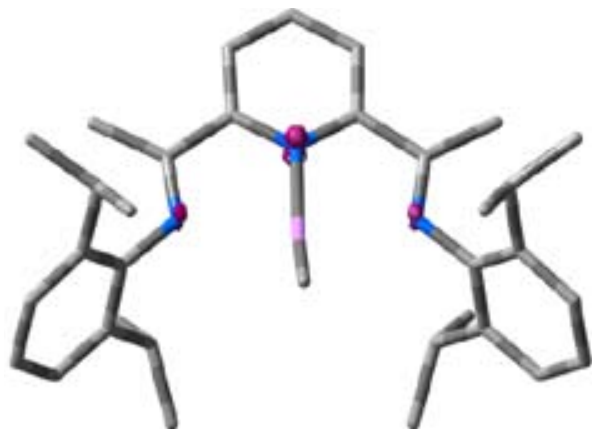

Fig. 7. Isosurface diagram for nucleophilic Fukui function $f^{+}(\mathbf{r})$ of compound 6 with contribution at the pyridine nitrogen atom (magenta colors correspond to positive $f^{+}(\mathbf{r})$ values; cutting value 0.01 a.u.). Hydrogen atoms are omitted for clarity.

Mulliken charge on the ligand by the absence and presence of the ether molecule was -0.58 and -0.62 respectively.

Once the methyl group makes the nucleophilic addition to the pyridine nitrogen atom, the higher $f^{+}(\mathbf{r})$ values for $\mathbf{7}$ are located at the imino groups (Figure 8). Even while 7 is stable for extended periods at room temperature, the ligand was easily deprotonated at the imine methyl group with loss of methane [7, 25]. Gibson et al. [25] provided strong evidence that this transformation occurred via the re-formation of MeLi which dissociates from the ligand and is then available to dedeuterate the ligand backbone. Additionally, the methyl group could be abstracted from the nitrogen atom by the mild electrophiles $i$ - $\mathrm{PrBr}$ and $\mathrm{FeCl}_{3}$, indicating that the alkylation at the nitrogen atom may be reversible.

\section{Concluding remarks}

The nucleophilic $N$-alkylation on pyridine is an unprecedented reaction throughout the history of chemistry, as Gibson, Gambarotta, and coworkers have pointed out. The local HSAB principle and the DFT local descriptors suggest that nucleophilic attack at the pyridine nitrogen atom of 2,6-bis(imino)pyridines 1 depends fundamentally on stereoelectronic rather than on

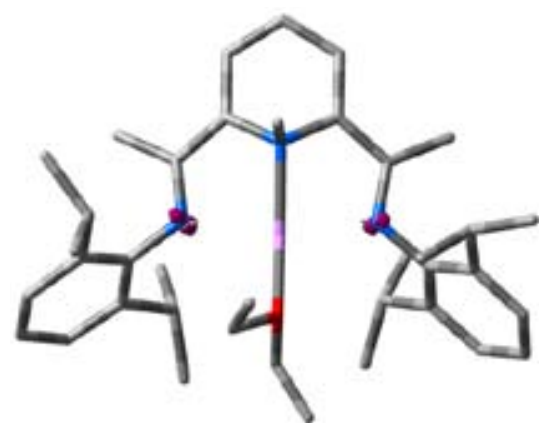

Fig. 8. Isosurface diagram for nucleophilic Fukui function $f^{+}(\mathbf{r})$ for 7 showing the positive $f^{+}(\mathbf{r})$ values at the imino groups of 7 (cutting value 0.01 a.u.). Hydrogen atoms are omitted for clarity. 
steric factors. The nucleophilic attack at the pyridine nitrogen atom of $\mathbf{1}$ occurs via an s-cis,s-cis-conformer. The ortho substitution in the aryl ring should not modify the nitrogen pyridine reactivity. The chelation of MeLi by the pyridine and imino nitrogen atoms does not modify the electrophilic behavior of the $[N, N, N]$ ligand; the soft pyridine nitrogen atom continues to be the most reactive site in the molecule for the methyl anion nucleophilic attack.

\section{Acknowledgments}

We thank CONACyT-México for financial support (F.M.) and Dr. Eduardo González (UAM-I, México) for many helpful discussions. We thank referee (1) for the suggestions for improving the article.

\section{References}

1. Reardon, D.; Conan, F.; Gambarotta, S.; Yap, G.; Wang, Q. J. Am. Chem. Soc., 1999, 121, 9318-9325.

2. Gibson, V. C.; Kimberley, B. S.; White, A. P. J.; Williams, D. J.; Howard, P. J. Chem. Commun. 1998, 313-314.

3. Britovsek, G. J. P.; Gibson, V. C.; Kimberley, B. S.; Maddox, P. J.; McTavish, S. J.; Solan, G. A.; White, A. P. J.; Williams, D. J. Chem. Commun. 1998, 849-850.

4. Small, B. L.; Brookhart, M.; Bennett, M. A. J. Am. Chem. Soc., 1998, 120, 4049-4050.

5. Bruce, M.; Gibson, V. C.; Redshaw, C.; Solan, G. A.; White, A. J. P.; Williams, D. J.; Chem. Commun. 1998, 2523-2524.

6. Clentsmith, G. K. B.; Gibson, V. C.; Hitchcock, P. B.; Kimberley, B. S.; Rees, C. W. Chem. Commun. 2002, 1498-1499.

7. Khorobkov, I.; Gambarotta, S.; Yap, G. P. A.; Budzelaar, P. H. M. Organometallics 2002, 21, 3088-3090.

8. Gázquez, J. L.; Méndez, F. J. Phys. Chem. 1994, 98, 4591-4593.

9. Méndez, F.; Gázquez, J. L.; J. Am. Chem. Soc. 1994, 116, 92989301.

10. Ayers, P. W.; Parr, R. G. J. Am. Chem. Soc. 2001, 123, $2007-$ 2017.

11. Chattaraj, P. K. J. Phys. Chem. A 2001, 105, 511-513.

12. Parr, R. G.; Yang, W. "Density Functional Theory of Atoms and Molecules", Oxford University Press, Oxford: UK, 1989.
13. Chandrakumar, K. R. S.; Pal, S. J. Phys. Chem. B 2001, 105, 45414544.

14. Méndez, F.; Galván, M.; Garritz, A.; Vela, A.; Gázquez; J. L. J. Mol. Struct. (THEOCHEM), 1992, 211, 81-86.

15. Gregus, Z.; Roos, G.; Geerlings, P.; Nemeti, B. Toxicol. Sci., 2009, 110, 282-292.

16. Pal, S.; Chandrakumar, K. R. S. J. Am. Chem. Soc. 2000, 122, 4145-4153.

17. Geerlings, P.; De Proft. F.; Langenaeker, W. Chem. Rev. 2003, 103, 1793-1874.

18. Poon, T.; Mundy, B. P.; Shattuck, T. W. J. Chem. Ed. 2002, 79, 264-267.

19. Gilardoni, F.; Weber, J.; Chermete, H.; Ward, T. R.; J. Phys. Chem. 1998, 102, 3607-3613.

20. Juaristi, E.; Cuevas, G.; Acc. Chem Res. 2007, 40, 961-970.

21. Frisch, M. J.; Trucks, G. W.; Schlegel, H. B.; Scuseria, G. E.; Robb, M. A.; Cheeseman, J. R.; Montgomery, J. A. Jr.; Vreven, T.; Kudin, K. N.; Burant, J. C.; Millam, J. M.; Iyengar, S. S.; Tomasi, J.; Barone, V.; Mennucci, B.; Cossi, M.; Scalmani, G.; Rega, N.; Petersson, G. A.; Nakatsuji, H.; Hada, M.; Ehara, M.; Toyota, K.; Fukuda, R.; Hasegawa, J.; Ishida, M.; Nakajima, T.; Honda, Y.; Kitao, O.; Nakai, H.; Klene, M.; Li, X.; Knox, J. E.; Hratchian, H. P.; Cross, J. B.; Bakken, V.; Adamo, C.; Jaramillo, J.; Gomperts, R.; Stratmann, R. E.; Yazyev, O.; Austin, A. J.; Cammi, R.; Pomelli, C.; Ochterski, J. W.; Ayala, P. Y.; Morokuma, K.; Voth, G. A.; Salvador, P.; Dannenberg, J. J.; Zakrzewski, V. G.; Dapprich, S.; Daniels, A. D.; Strain, M. C.; Farkas, O.; Malick, D. K.; Rabuck, A. D.; Raghavachari, K.; Foresman, J. B.; Ortiz, J. V.; Cui, Q.; Baboul, A. G.; Clifford, S.; Cioslowski, J.; Stefanov, B. B.; Liu, G.; Liashenko, A.; Piskorz, P.; Komaromi, I.; Martin, R. L.; Fox, D. J.; Keith, T.; Al-Laham, M. A.; Peng, C. Y.; Nanayakkara, A.; Challacombe, M.; Gill, P. M. W.; Johnson, B.; Chen, W.; Wong, M. W.; Gonzalez, C.; Pople, J. A. Gaussian 03, Revision C.02; Gaussian, Inc.:Wallingford, CT, 2004.

22. GaussView 3.0, Gaussian, Inc. Carnegie Office Park - Building 6 Pittsburg PA 15106 USA, Copyright (c) 2000-2003 Semichem, Inc.

23. The trend of the experimental values for the halogen hardness, places the $\mathrm{C}_{6} \mathrm{H}_{5} \mathrm{NH}_{2}$ and $\mathrm{Me}$ nucleophiles as soft and softer groups respectively: $\eta \mathrm{F}(7.01 \mathrm{eV})>\eta \mathrm{Cl}(4.70 \mathrm{eV})>\eta \mathrm{C}_{6} \mathrm{H}_{5} \mathrm{NH}_{2}(4.40$ $\mathrm{eV})>\eta \mathrm{Br}(4.24 \mathrm{eV})>\eta \mathrm{Me}(4.0 \mathrm{eV})>\eta \mathrm{I}(3.70 \mathrm{eV})$, see Pages 75, 80 and 86, Pearson, R. G. "Chemical Hardness", Wiley-VCH, Weinheim: Germany, 1997.

24. Parr, R. G.; Pearson, R.G. J. Am. Chem. Soc., 1983, 105, 75127516.

25. Blackmore, I. J.; Gibson, V. C.; Hitchcock, P. B.; Rees, C. W.; Kimberley, B. S.; Williams, D. J.; White, A. P. J. J. Am. Chem. Soc., 2005, 127, 6012-6020. 